\title{
Engineering the Oryza sativa cell wall with rice NAC transcription factors regulating secondary wall formation
}

\section{Kouki Yoshida ${ }^{1}$, Shingo Sakamoto ${ }^{2}$, Tetsushi Kawai ${ }^{2}$, Yoshinori Kobayashi ${ }^{3}$, Kazuhito Sato ${ }^{4}$, Yasunori Ichinose ${ }^{5}$,Katsuro Yaoi ${ }^{2}$, Miho Akiyoshi-Endo ${ }^{1}$, Hiroko Sato $^{6}$, Tadashi Takamizo $^{6}$, Masaru Ohme-Takagi ${ }^{2,7}$ and Nobutaka Mitsuda ${ }^{2} *$}

\author{
${ }^{1}$ Technology Center, Taisei Corporation, Yokohama, Japan \\ ${ }^{2}$ Bioproduction Research Institute, National Institute of Advanced Industrial Science and Technology, Tsukuba, Japan \\ ${ }^{3}$ Japan Bioindustry Association, Tsukuba, Japan \\ ${ }^{4}$ Green Sogna Inc., Tsukuba, Japan \\ ${ }^{5}$ National Institute of Crop Science, Tsukuba, Japan \\ ${ }^{6}$ National Institute of Livestock and Grassland Science, National Agriculture and Food Research Organization, Nasushiobara, Japan \\ ${ }^{7}$ Institute for Environmental Science and Technology, Saitama University, Saitama, Japan
}

\section{Edited by:}

Chandrashekhar Pralhad Joshi, Michigan Technological University, USA

\section{Reviewed by:}

Kevin Davies, New Zealand Institute for Plant and Food Research, New Zealand

Kyung-Hwan Han, Michigan State University, USA

\section{*Correspondence:}

Nobutaka Mitsuda, Bioproduction Research Institute, National Institute of Advanced Industrial Science and Technology, Central 6, 1-1-1 Higashi, Tsukuba, Ibaraki 305-8566, Japan e-mail: nobutaka.mitsuda@aist.go.jp
Plant tissues that require structural rigidity synthesize a thick, strong secondary cell wall of lignin, cellulose and hemicelluloses in a complicated bridged structure. Master regulators of secondary wall synthesis were identified in dicots, and orthologs of these regulators have been identified in monocots, but regulation of secondary cell wall formation in monocots has not been extensively studied. Here we demonstrate that the rice transcription factors SECONDARY WALL NAC DOMAIN PROTEINs (SWNs) can regulate secondary wall formation in rice (Oryza sativa) and are potentially useful for engineering the monocot cell wall. The OsSWN1 promoter is highly active in sclerenchymatous cells of the leaf blade and less active in xylem cells. By contrast, the OsSWN2 promoter is highly active in xylem cells and less active in sclerenchymatous cells. OsSWN2 splicing variants encode two proteins; the shorter protein (OsSWN2S) has very low transcriptional activation ability, but the longer protein (OsSWN2L) and OsSWN1 have strong transcriptional activation ability. In rice, expression of an OsSWN2S chimeric repressor, driven by the OsSWN2 promoter, resulted in stunted growth and para-wilting (leaf rolling and browning under normal water conditions) due to impaired vascular vessels. The same OsSWN2S chimeric repressor, driven by the OsSWN1 promoter, caused a reduction of cell wall thickening in sclerenchymatous cells, a drooping leaf phenotype, reduced lignin and xylose contents and increased digestibility as forage. These data suggest that OsSWNs regulate secondary wall formation in rice and manipulation of OsSWNs may enable improvements in monocotyledonous crops for forage or biofuel applications.

Keywords: NAC trascription factor, secondary cell wall, rice, genetic modification, CRES-T

\section{INTRODUCTION}

The secondary wall is a plant-specific, stiff and thick cell wall composed of lignin, cellulose and hemicelluloses in a complicated bridged structure. The secondary wall is synthesized just outside the plasma membrane of vascular vessels and fiber cells in xylem, which require mechanical rigidity and stability to retain water in the vessel, endure the internal pressure of water transport and support the plant's aerial structures. Some species also produce secondary walls in the internal cell layer of anthers and siliques; the different shrinkage rates of cell layers with or without secondary walls produces tension that promotes dehiscence of anthers and siliques during dehydration (Keijzer, 1987; Mitsuda and Ohme-Takagi, 2008). In contrast to dicots and conifers, monocotyledonous plants do not possess vascular cambium but do develop secondary walls within the leaf blade and culm, and in vascular vessels. However, the composition of monocot secondary cell walls differs from that of dicots (Carpita and Gibeaut, 1993; Yokoyama and Nishitani, 2004) and the developmental regulation of secondary wall formation in monocots has not been well characterized, except for identification of some enzymes and related proteins (Li et al., 2003; Hirano et al., 2010; Kotake et al., 2011).

Some secondary cell wall components can negatively affect downstream uses of plant biomass. For example, monocots are traditionally important forage crops; however, high lignin content results in poor digestibility. Also, several monocot plants, such as miscanthus and switchgrass, have recently emerged as potential feedstock crops for cellulosic biofuels (Schmer et al., 2008); however, high lignin can adversely affect the conversion of cellulose to fermentable sugars. In addition, high arabinoxylan and xylan contents in primary and secondary cell walls of monocots may require an additional xylose fermentation after saccharification. By contrast, pyrolytic biofuels applications may benefit from high lignin content, which increases energy density. Therefore, elucidation of the mechanisms regulating secondary wall biosynthesis in monocots has the potential to improve crops for multiple important applications. 
The regulation of secondary wall formation has been extensively studied in the model dicot Arabidopsis thaliana. These studies revealed that a specific set of NAC transcription factors acts as master regulators of vascular vessel differentiation and secondary wall formation in fiber cells (Kubo et al., 2005; Mitsuda et al., 2005, 2007; Zhong et al., 2006; Ko et al., 2007; Mitsuda and Ohme-Takagi, 2008). For example, the expression of chimeric repressors of some VASCULAR ASSOCIATED NAC DOMAIN PROTEIN (VND) genes inhibited the differentiation of vascular vessels (Kubo et al., 2005). Also, the double knockout of NAC SECONDARY WALL THICKENINGS PROMOTING FACTOR 1 (NST1) and NST2 showed an indehiscent anther phenotype due to failure of secondary wall formation in the anther endothecium (Mitsuda et al., 2005). The double knockout of NST1 and NST3/SECONDARY WALL ASSOCIATED NAC DOMAIN PROTEIN 1 (SND1) caused a complete absence of secondary wall in fiber cells of stem and hypocotyl (Mitsuda et al., 2007). The nst1 nst 3 double mutant and the nst 1 single mutant also showed indehiscent siliques caused by the absence of secondary wall in the valve endocarp layer and valve margin (Mitsuda and Ohme-Takagi, 2008). The VNDs and NSTs are related NAC families, forming small adjacent subfamilies in the NAC transcription factor family phylogenetic tree (Mitsuda et al., 2005). Overexpression of these NAC proteins similarly induced ectopic secondary wall formation in various tissues (Kubo et al., 2005; Mitsuda et al., 2005; Zhong etal., 2006). Several MYBs and other transcription factors act downstream of the NACs in a complicated regulatory network (Zhong et al., 2007; Soyano et al., 2008; Zhou et al., 2009; Ko et al., 2009, 2012; Bhargava et al., 2010; Wang et al., 2010; Li et al., 2011; Cassan-Wang et al., 2013). Several orthologous genes in poplar and Medicago truncatula (Barrel Medic) also function in secondary wall formation (Zhao et al., 2010; Zhong et al., 2011b). In poplar, a new systematic nomenclature was proposed for the VND and NST orthologs; according to this nomenclature, the genes would be named WOOD-ASSOCIATED NAC DOMAINs (WNDs) or VND, NST/SND AND SMB RELATED PROTEINS (VNSs) because their expression patterns are not readily classified into either VND or NST types as in Arabidopsis (Ohtani et al., 2011; Zhong et al., 2011b). In monocots, several rice and corn NST orthologs, which were renamed SECONDARY WALL NAC DOMAIN PROTEINs (SWNs), were recently shown to restore the drooping phenotype of Arabidopsis nst 1 nst3 double mutants and induce ectopic secondary formation when overexpressed in Arabidopsis (Zhong et al., 2011a). However, it remains unclear whether SWNs actually regulate secondary wall formation in monocots.

In this study, we demonstrate that rice OsSWN proteins can regulate secondary wall formation in rice, and that the expression of a chimeric repressor of OsSWN2 improves digestibility as forage by causing a reduction of lignin content.

\section{MATERIALS AND METHODS PREPARATION OF PHYLOGENETIC TREE}

NAC transcription factor genes similar to NST1 were identified by TBLASTN searches of all coding sequences (CDSs) of Arabidopsis and rice, using NST1 as query. Full-length amino-acid sequence alignment was prepared using MAFFT (Katoh et al.,
2002) and the phylogenetic tree was built by the Neighbor-Joining method with MEGA5 (Tamura et al., 2011). The percentage of replicate trees in which the associated taxa clustered together in the bootstrap test (1000 replicates) is shown next to the branches.

\section{PLASMID CONSTRUCTION}

ProOsACT1:OsSWN1/2S-SRDX, 35S:OsSWN1/2S and ProNST3: OsSWN1/2S were prepared based on pActSRDXG, p35SG and pNST3_EntG vectors, which were previously described (Mitsuda et al., 2005, 2006, 2007). The CDSs of OsSWN1 and OsSWN2S were amplified with the following primer sets. For OsSWN1, OsNST2N (5'-GATGAGCATATCGGTGAACGGGCAGTCGGT$\left.3^{\prime}\right)$, OsNST2C (5'-TACGTTATTCATGGTCGTCAAGTCTGCGT G- $\left.3^{\prime}\right)$ and OsNST2S (5'-TCAACGGTCACCGTCGAGCAGTTGC TCGGG-3'). For OsSWN2S, OsNST1N (5'-GATGAGCATCTCGG TGAACGGGCAGTCGTG-3'), OsNST1C (5'-TGGCCCAGTCCG TGCGGTGGTGGT- $3^{\prime}$ ) and OsNST1S (5'-TCATGGCCCAGTCC GTGCGGTGGTGGT-3'). Each CDS was ligated into the SmaI sites of the pActSRDXG, p35SG and pNST3_EntG vectors. ProZmUBQ1:OsSWN1/2S-SRDX was prepared similarly, based on the pUBQ1SXG vector, which was modified from the pActSRDXG vector. For the cloning of OsSWN promoters, the following primer sets were used. For OsSWN1, OsNST2pFA3 (5'-AAATTTGGCGCGCTTGCCGACGCTCGGAGCGTGCGAG CTG- $\left.3^{\prime}\right)$ and OsNST2proR2Bam (5'-AAATTTGGATCCACCGAC TGCCCGTTCACCGATATGC-3'). For OsSWN2, OsNST1pFA (5'-AAATTTGGCGCGCCACATATGTTGGATGTATTCTCCGAA A-3 $\left.{ }^{\prime}\right)$ and OsNST1pRB ( $5^{\prime}$-AAATTTGGATCCATTGATGATCTTC TTCTTCTTCTCCTT- $\left.3^{\prime}\right)$. The amplified fragments were cloned into the AscI/BamHI site of the pSRDX_NOSG vector, which does not have a plant promoter, and into the pGUS_Ent vector for promoter-GUS analysis. The OsSWN CDSs were cloned into the SmaI site of promoter-inserted pSRDX_NOSG vectors. The contents of these vectors were transferred into the binary vector pBCKH (Mitsuda etal., 2006) to prepare transgenic Arabidopsis and rice. For the reporter plasmid for the transient effector-reporter analysis, two pairs of synthetic oligonucleotides; AscNSTx3Not_F (5'CGCGCCGTATACCTTGTGAATGAAGAAACTGTATACCTTGT GAATGAAGAAACTGTATACCTTGTGAATGAAGAAACTGC-3' and AscNSTx3Not_R (5'-GGCCGCAGTTTCTTCATTCACAAGG TATACAGTTTCTTCATTCACAAGGTATACAGTTTCTTCATTC ACAAGGTATACGG-3'), AscmSNBEx3Not_F (5'-CGCGCCGTAT ACAAGGTGAATGAAGAAACTGTATACAAGGTGAATGAAGAA ACTGTATACAAGGTGAATGAAGAAACTGC-3') and AscmSNBEx3Not_R (5'-GGCCGCAGTTTCTTCATTCACCTTGTATACAG TTTCTTCATTCACCTTGTATACAGTTTCTTCATTCACCTTGT ATACGG-3') containing three tandem repeats of the binding sequence for NST transcription factors (SNBE; Zhong et al., 2010) or mutated SNBEs were annealed and ligated into the pTATA_LUC_HSP vector, which harbors a TATA box, translational enhancer sequence, firefly luciferase gene and heat shock protein (HSP; Nagaya et al., 2010) terminator sequence. For the OsSWN2L effector plasmid, the CDS of OsSWN2L (GenBank accession number JN634071) was artificially synthesized and cloned into the SmaI site of the p35SG vector. 


\section{PLANT CULTIVATION AND TRANSFORMATION}

Arabidopsis thaliana ecotype Columbia-0 was grown on soil at $23^{\circ} \mathrm{C}$, under a $16 \mathrm{~h}$ day $/ 8 \mathrm{~h}$ night cycle. For the genetic transformation, the floral dip method was employed (Clough and Bent, 1998). Agrobacterium-mediated transformation of rice cultivar "Nipponbare" was performed as described previously (Mitsuda et al., 2006). Regenerated rice was grown in soil for rice seedlings under natural sunlight in a closed greenhouse at $22-32^{\circ} \mathrm{C}$, transferred to squareshaped plastic pots after 1-2 weeks and cultivated under mostly submerged water conditions (water height from the base of pot: 60-90 mm).

\section{LIGHT AND FLUORESCENCE MICROSCOPY}

For GUS staining, plant tissues were incubated in $100 \mathrm{mM}$ sodium phosphate buffer, $\mathrm{pH} 7.0$, containing $0.1 \%$ Triton X-100, $1 \mathrm{mM} 5$-bromo-4-chloro-3-indolyl- $\beta$-D-glucuronide, and $0.5 \mathrm{mM}$ potassium ferricyanide at $37^{\circ} \mathrm{C}$ for up to $16 \mathrm{~h}$. Stained or harvested leaf tissue was embedded in 5\% agar and $100-\mu \mathrm{m}$ sections were prepared with a vibrating microtome (HM-650V; Microm Inc.). All observations by light and fluorescence microscopy were made with the Axioskop2 plus system (Zeiss Inc.). For observations of lignin autofluorescence, we used a filter with the following specifications: excitation filter: $365 \mathrm{~nm}$ short pass; dichroic mirror: $395 \mathrm{~nm}$; emission filter: $400 \mathrm{~nm}$ long pass. To observe ectopic secondary wall thickening, we cleared tissues by incubating them overnight in $70 \%$ lactic acid at $50^{\circ} \mathrm{C}$. To stain lignin specifically, sections were stained with $2 \%(\mathrm{w} / \mathrm{v})$ phloroglucinol in $95 \%$ ethanol for 2-5 min, washed in $10 \mathrm{~N} \mathrm{HCl}$ for $1 \mathrm{~min}$, and mounted in $5 \mathrm{~N} \mathrm{HCl}$.

\section{TRANSIENT EFFECTOR-REPORTER ANALYSIS}

Transient effector-reporter analysis using protoplasts isolated from long-day-grown Arabidopsis rosette leaves was performed as described (Fujikawa and Kato, 2007). Briefly, 0.5-1.0 mm strips of sliced leaves were incubated in an enzyme solution containing $1 \%(\mathrm{w} / \mathrm{v})$ cellulase "onozuka" R10 (Yakult Pharmaceutical Inc., Japan), 0.25\% (w/v) macerozyme "onozuka” R10 (Yakult), 0.4 M mannitol, $20 \mathrm{mM}$ MES, $20 \mathrm{mM} \mathrm{KCl,} 10 \mathrm{mM} \mathrm{CaCl}_{2}$, and $5 \mathrm{mM}$ 2 -mercaptoethanol for $3 \mathrm{~h}$ with shaking at $50 \mathrm{rpm}$. The solution was then filtered through 75- $\mu \mathrm{m}$ nylon mesh (BD Biosciences Inc., USA) and collected by centrifugation at $100 \times g$ for $5 \mathrm{~min}$. The pellet was washed twice with W5 buffer containing $150 \mathrm{mM} \mathrm{NaCl}$, $125 \mathrm{mM} \mathrm{CaCl}_{2}, 5 \mathrm{mM} \mathrm{KCl}$, and $2 \mathrm{mM} \mathrm{MES}$, followed by centrifugation at $100 \times g$ for $5 \mathrm{~min}$. The protoplast suspension was kept at $4^{\circ} \mathrm{C}$ for $30 \mathrm{~min}$. After removing the supernatant, the protoplast cells were resuspended in $\mathrm{MMg}$ solution containing $0.4 \mathrm{M}$ mannitol, $15 \mathrm{mM} \mathrm{MgCl}_{2}$, and $4 \mathrm{mM} \mathrm{MES}$ and then adjusted to $1.5-2.0 \times 10^{5}$ cells $/ \mathrm{ml}$. The protoplast suspension, plasmids and transduction solution containing $40 \%$ polyethylene glycol, $0.2 \mathrm{M}$ mannitol, and $0.1 \mathrm{M} \mathrm{CaCl}_{2}$ were thoroughly mixed with a vortex mixer at $900 \mathrm{rpm}$ for $15 \mathrm{~s}$ and then kept at room temperature for $10 \mathrm{~min}$. After introducing the plasmids, the protoplasts were washed three times with W5 buffer and then incubated at $22^{\circ} \mathrm{C}$ for $18 \mathrm{~h}$ in dark. Firefly luciferase driven by a minimal promoter with three tandem repeats of the NST binding sequence or its mutated version was employed as a reporter. The details of its construction are described in the Section "Plasmid Construction."
Along with the reporter construct, 35S:OsSWN1, 35S:OsSWN2S or 35S:OsSWN2L was co-introduced as the effector. As the internal reference, a modified Renilla luciferase ( $h R L U C$; Promega Inc.) gene driven by the 35 S promoter (phRLHSP; Nagaya et al., 2010) was used to normalize the data.

\section{MEASUREMENT OF YOUNG'S MODULUS}

$30 \mathrm{~mm}$-long explants were excised from the base of inflorescence stems of 14 2-month-old Arabidopsis plants. They were immediately fixed by immersion in $85^{\circ} \mathrm{C}$ methanol for $5 \mathrm{~min}$ and stored in methanol at room temperature. They were rehydrated and treated with $0.2 \mathrm{mg} / \mathrm{ml}$ pronase from Actinomyces spp. (Actinase E, Kaken Pharmaceutical Inc., Japan) in $50 \mathrm{mM}$ potassium-phosphate buffer ( $\mathrm{pH} 7.0$ ) containing $5 \%$ ethanol for $18 \mathrm{~h}$ after pre-incubation in protease solution for $2 \mathrm{~h}$ at $37^{\circ} \mathrm{C}$. The protease-treated explants were washed with distilled water and stored in methanol. Force-extension relationships were measured with a tensile-testing instrument (Auto com-200N A/C, TS Engineering Inc., Japan). After measurement, the explant was dried and weighed for calculation of its mass per length. Young's modulus was calculated by employing Cleland's formula (Cleland, 1967).

\section{ANALYSIS OF WATER TRANSPORT}

To analyze water transport in ProOsSWN2:OsSWN2S-SRDX rice, we employed Fantasy dye solution for the staining of cut leaves (red type, Palace chemical Inc., Japan; Murakami et al., 2006). The petioles of fully developed rice leaves were immersed in the Fantasy dye solution and observed for up to 120 minutes. After staining, leaves $(0.07-0.35 \mathrm{~g}$ fresh weight) were cut into ca. $3 \mathrm{~cm}$ length pieces, fixed and stored in $5 \mathrm{ml} \mathrm{FAA}$ solution [formaldehyde, acetic acid, and ethanol $(8: 1: 1 \mathrm{v} / \mathrm{v})]$ at room temperature. Most of the red dye was extracted from the leaf tissue with FAA in a week. The absorption spectra of the extracts were scanned and we found the absorbance at $550 \mathrm{~nm}$ was specific for extracts from cut leaves. The absorbance at $625 \mathrm{~nm}$ was used as a blank in each extract. Delta absorbance (550-625 nm) was converted into arbitrary and quantitative units of dye uptake by leaves with a standard curve, $y$ (units $/ \mathrm{ml})=0.578 \times$ delta absorbance -0.0072 .

\section{TEM IMAGING AND ANALYSIS}

Short pieces of rice leaf blades were fixed in $30 \mathrm{mM}$ HEPES containing 2\% paraformaldehyde and $2 \%$ glutaraldehyde then fixed in HEPES containing 2\% osmium tetroxide. Fixed tissues were embedded in Q651 resin (Nissin EM Inc., Japan). Sections of 80-90 nm thick were post-stained with uranyl acetate and lead citrate and observed with a JEM1200EX transmission electron microscope (JEOL Inc., Japan) at an accelerating voltage of $80 \mathrm{kV}$. Thickness of secondary walls in several layers of cortical fiber cells beneath the epidermis was measured for more than 10 cells in each of 7-9 pictures.

\section{THE ANALYSIS OF SACCHARIFICATION RATE, LIGNIN CONTENT AND ACID DETERGENT FIBER}

Culms of rice were collected after the harvest of mature seeds and dried at $70^{\circ} \mathrm{C}$ for 1 week. The amylase-treated sample was prepared as follows. The samples were ground and the resulting powder $(100 \mathrm{mg})$ was treated with amylase solution $(3 \mathrm{U} / \mathrm{ml}$ of $\alpha$-Amylase 
from porcine pancreas and $30 \mathrm{U} / \mathrm{ml}$ of amyloglucosidase from Aspergillus niger in $0.1 \mathrm{M}$ sodium maleate buffer at $\mathrm{pH} 6.0$ ) at $37^{\circ} \mathrm{C}$ for $16 \mathrm{~h}$ with shaking. After amylase treatment, the sample was washed with ethanol and water, then dried at $65-70^{\circ} \mathrm{C}$ for 3 days and designated as the amylase-treated sample. The saccharification rate of the amylase-treated sample was measured by enzymatic reaction with Celluclast 1.5 land Novozyme 188 (Novozymes Inc., Japan) as previously described (Iwase et al., 2009).

We quantified lignin content by the acetyl bromide method, following the protocol of Johnson et al. (1961) modified by Morrison (1972); Iiyama and Wallis (1988) and Hatfield et al. (1999). The weight of the amylase-treated sample (1.00-2.00 mg per tube) was measured in glass culture tubes $(16 \times 100 \mathrm{~mm})$ fitted with Teflonlined screw caps. $0.5 \mathrm{ml}$ of freshly prepared acetyl bromide reagent [25\% (v/v) acetyl bromide (Wako Inc., Japan) in glacial acetic acid] was added and heated at $50^{\circ} \mathrm{C}$ for $2 \mathrm{~h}$. After heating, acetic acid $(1.5 \mathrm{ml})$ was added and the sample was centrifuged at $3000 \mathrm{~g}$ for $15 \mathrm{~min}$ with a swing rotor at room temperature. The supernatant $(0.4 \mathrm{ml})$ was transferred to a $1.5 \mathrm{ml}$ tube that contained $0.3 \mathrm{~mL}$ of $0.3 \mathrm{M} \mathrm{NaOH}$ and $0.5 \mathrm{~mL}$ of acetic acid. After mixing, $0.1 \mathrm{ml}$ of $0.5 \mathrm{M}$ hydroxylamine was added to each tube and the absorbance at $280 \mathrm{~nm}$ was measured. Lignin treated with alkali carboxylate (Sigma Inc., USA) was used as a standard for lignin content. All measurements were run in triplicate for each sample.

Digestibility as forage was analyzed by a modified method as described previously (Abe, 1988). Approximately $0.5 \mathrm{~g}$ of sample was boiled with $10 \mathrm{ml}$ of distilled water in a screw cap bottle for $1 \mathrm{~min}$ on a hot plate to denature starch. After cooling, $35 \mathrm{ml}$ of enzyme solution consisting of $0.2 \%$ cellulase and $0.01 \% \alpha$ amylase in $0.1 \mathrm{M}$ acetate buffer was added and incubated at $40^{\circ} \mathrm{C}$ with shaking for $17.5 \mathrm{~h}$. The sample was filtered through filter paper (Toyo 5A, $125 \mathrm{~mm}$ ) and the residue was washed three times with distilled water. The residue in the filter paper was dried at $105^{\circ} \mathrm{C}$ overnight and weighed after cooling in a desiccator. Digestibility of the sample was calculated by the following equation: $100-100\left(\mathrm{~A}^{\prime}-\mathrm{A}\right) / \mathrm{S}(\mathrm{G} / 100)$. S, A, G, $\mathrm{A}^{\prime}$ represent weight of the sample, weight of container + filter paper, dry matter percentage and weight of container + filter paper + residue, respectively.

Acid detergent fiber (ADF) was analyzed according to Van Soest (1963). $50 \mathrm{ml}$ of acid detergent (AD) solution consisting of $1 \mathrm{~N}$ $\mathrm{H}_{2} \mathrm{SO}_{4}$ and $2 \%(\mathrm{w} / \mathrm{v}$ ) CTAB was added to about $0.5 \mathrm{~g}$ of sample and placed on the heating unit for $60 \mathrm{~min}$, after which the solution was filtered through a fritted glass. After washing with distilled water and acetone, the fritted glass crucible with residue was dried at $105^{\circ} \mathrm{C}$ overnight. After cooling in a desiccator and weighing, the crucible with residue was placed at $500^{\circ} \mathrm{C}$ for $3-4 \mathrm{~h}$ in a muffle furnace. After cooling, the ash was weighed. ADF was calculated by the following equation: $100(\mathrm{~A}-\mathrm{B}) / \mathrm{S}(\mathrm{G} / 100)$. S, A, B and $\mathrm{G}$ represent weight of the sample, weight of the crucible + residue, weight of the crucible + ash and dry matter percentage, respectively.

\section{SUGAR COMPOSITION ANALYSIS}

Matrix polysaccharides of cell wall in culm sample (3-5 mg) treated with $\alpha$-amylase and amyloglucosidase were hydrolyzed in $1 \mathrm{ml}$ of $2 \mathrm{M}$ trifluoroacetic acid (TFA) at $121^{\circ} \mathrm{C}$ for $60 \mathrm{~min}$ (Albersheim et al., 1967). After cooling to room temperature, the hydrolysate (TFA soluble fraction) was separated from TFA insoluble residues by centrifugation at $2000 \times g$ for $5 \mathrm{~min}$ using a swing rotor and then dried at $80^{\circ} \mathrm{C}$ with $\mathrm{N}_{2}$ aeration. The dried sugars were dissolved in distilled water for the analysis of sugar composition. The TFA insoluble residues were rinsed with distilled water and ethanol and then completely dried at $80^{\circ} \mathrm{C}$ for $24 \mathrm{~h}$. The dried residue was treated with $200 \mu \mathrm{l}$ of $72 \%$ $(\mathrm{w} / \mathrm{w})$ sulfuric acid and incubated for $1 \mathrm{~h}$ at room temperature with agitation. Then the mixture was diluted into $4 \mathrm{ml}$ of distilled water and autoclaved at $121^{\circ} \mathrm{C}$ for $1 \mathrm{~h}$. Sulfuric acid hydrolysate (TFA insoluble fraction) was neutralized with calcium carbonate and then used for the sugar composition analysis. Mono-saccharide composition of each hydrolysate was analyzed by Shimadzu Prominence HPLC system (Shimadzu Inc., Japan) with fluorescence detector (RF-AXL, Shimadzu) as described by Kawai et al. (2012). The standard sugars used in this study were glucose, xylose, arabinose, rhamnose, galactose, and fucose (Wako Pure Chemical Industry Inc., Japan). Samples were separated with Asahipak NH2P-50 4E (Showa Denko Inc., Japan) with guard column Asahipak NH2P-50G 4A (Showa Denko Inc.) and Optiguard DVB (Lab Lab Company Inc., Japan) under $45^{\circ} \mathrm{C}$ at a flow rate of $0.8 \mathrm{ml} / \mathrm{min}$. The mobile phase was $0.3 \%$ phosphoric acid:acetonitrile (15:85 v/v).

\section{RESULTS}

\section{OsSWN PROMOTERS ARE ACTIVE IN RICE XYLEM CELLS}

To analyze how secondary wall formation in rice is regulated and to determine which promoter is most suitable for the manipulation of rice secondary walls, we surveyed rice NAC transcription factor genes that are similar to Arabidopsis NSTs, which act as master regulators of secondary wall formation. We found two close orthologous genes (Figure 1A), OsSWN1 (Os06g0131700) and OsSWN2 (Os08g0115800), which were previously reported by Zhong et al. (2011a). We tested the promoter activities of these genes using $\beta$-glucuronidase (GUS) as a reporter, generating transgenic rice expressing ProOsSWN1:GUS and ProOsSWN2:GUS. The approximately $3 \mathrm{kbp}$ promoter regions of both OsSWN1 and OsSWN2 were active in leaf veins but examination of leaf cross sections revealed slight differences in their expression patterns (Figures 1B-G). The OsSWN2 promoter was particularly active in bundle sheath, including vascular vessels in the xylem (Figures 1C,E,G) and the OsSWN1 promoter was preferentially active in several layers of sclerenchymatous cells beneath the epidermis in addition to the bundle sheath (Figures 1B,D,F). This pattern of OsSWN1 promoter activity was consistent with the previously reported in situ RNA hybridization data (Zhong et al., 2011a).

\section{OsSWN1 AND 0sSWN2L, BUT NOT OsSWN2S, CAN ACTIVATE SECONDARY WALL FORMATION IN ARABIDOPSIS}

Because the OsSWN1 and 2 promoters were active in tissues where secondary walls develop, we next tested whether the OsSWN1 and 2 proteins could activate secondary wall formation. As previously shown, overexpression of NST1, NST2 and NST3 induced ectopic deposition of secondary wall in various aboveground organs of Arabidopsis (Mitsuda et al., 2005, 2007). To test the ability of OsSWN proteins to induce secondary wall deposition, 


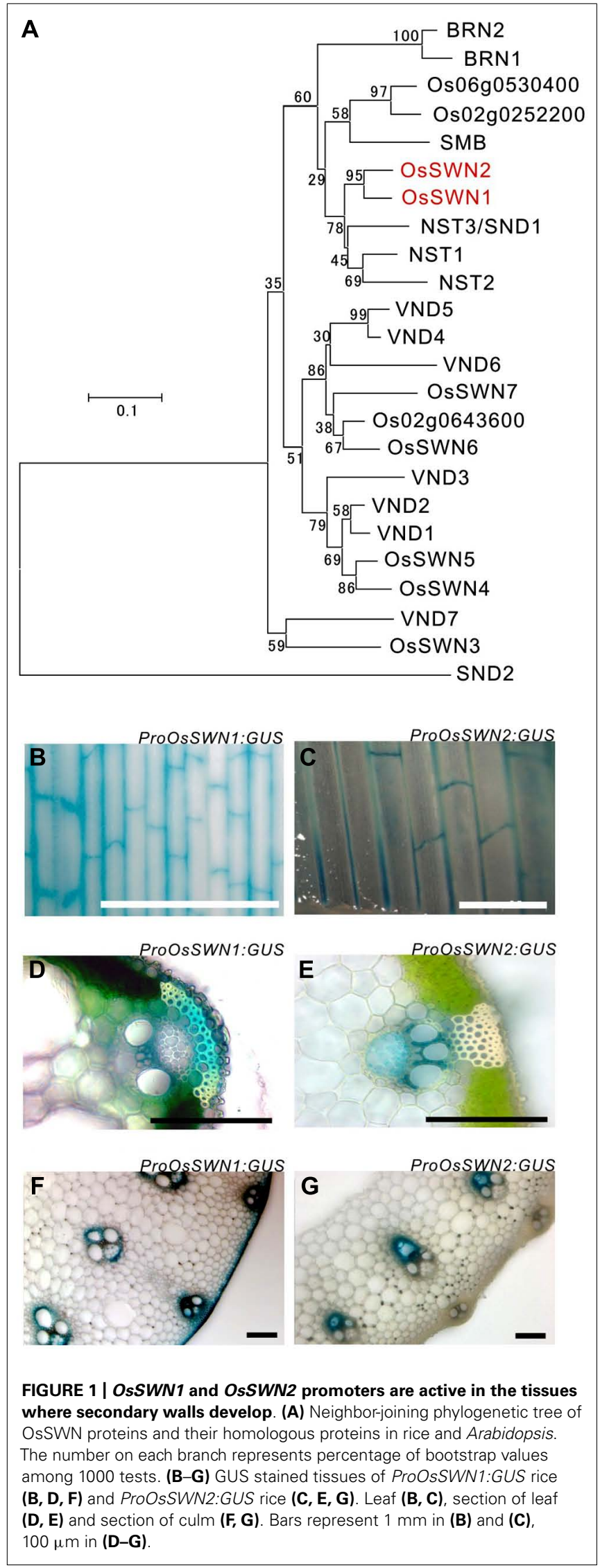

we obtained cDNAs for each protein (AK119784 for OsSWN1; AK109860 and JN634071 for OsSWN2; The Rice Full-Length cDNA Consortium, 2003; Satoh etal., 2007). We found that OsSWN2 produces two alternatively spliced forms that encode proteins of different lengths. The predicted protein from the AK109860 cDNA (OsSWN2S) is shorter than the predicted protein from the JN634071 cDNA (OsSWN2L) and seems to lack the transcriptional activation domain. OsSWN2L was not described in the most recent study (Zhong et al., 2011a) but was recently registered in GenBank. We made overexpression constructs for OsSWN1 and OsSWN2S, and transformed Arabidopsis with these constructs. Overexpression of OsSWN2S in Arabidopsis did not induce any ectopic secondary wall formation, but overexpression of OsSWN1 strongly induced ectopic secondary wall formation in Arabidopsis (Figures 2A,B; Zhong et al., 2011a). We also transformed OsSWN expression constructs into nst1-1 nst3-1 mutants, using OsSWN cDNAs expressed under the control of the NST3 promoter, which is preferentially active in the fiber cells of the inflorescence stem. We found that, consistent with the results of ectopic expression, OsSWN1, but not OsSWN2S, induced secondary wall formation and restored the fragile-stem phenotype of nst1-1 nst3-1 double knockout Arabidopsis plants when it was expressed under the control of the NST3 promoter (Figures 2C-F).

We next directly tested whether OsSWN1 and 2S/L can activate transcription. Based on its ability to induce ectopic secondary wall formation and to rescue the nst1-1 nst3-1 mutant, we hypothesized that OsSWN1 may act as a strong activator. Also, based on its length, OsSWN2L may act as an activator, but OsSWN2S likely lacks the ability to activate transcription. To test the activation activities of OsSWN1 and OsSWN2S/L, we performed transient effector-reporter experiments using Arabidopsis protoplasts derived from rosette leaves. For the reporter, we used a construct with three repeats of the SNBE sequence, which was previously reported to be a consensus binding site for NST transcription factors (Zhong et al., 2007) and we used a mutated sequence (mSNBE) as a negative control (Figure 3A). As expected, the OsSWN1 effector activated the expression of the reporter gene by as much as 20 -fold, and the OsSWN2L effector activated the reporter more than 30-fold (Figure 3B). By contrast, OsSWN2S showed very weak activation compared with the control effector (VAMP722; Figure 3B). However, when OsSWN2S was fused with the VP16 activation domain derived from herpes simplex virus (OsSWN2S$V P 16)$, the effector activated the reporter gene more than 20-fold (Figure 3B). In the negative control, OsSWN1, OsSWN2S-VP16 and OsSWN2L showed very little activation of reporter expression driven by the repeated mSNBE (Figure 3C). These results indicate that OsSWN1, OsSWN2S and OsSWN2L bind to the SNBE sequence specifically but OsSWN2S does not have adequate activation activity. We further tested whether OsSWN1 can activate native promoters of Arabidopsis genes that are known to function downstream of NST transcription factors. As shown in Figure 3D, OsSWN1 activated promoters of MYB46, CELLULOSE SYNTHASE A 7 (CESA7), FRAGILE FIBER 8 (FRA8) and Caffeoyl-CoA 3-O-methyltransferase 1 (CCoAOMT1), suggesting that OsSWN1 induces secondary wall formation by a mechanism similar to that of Arabidopsis NST transcription factors. 

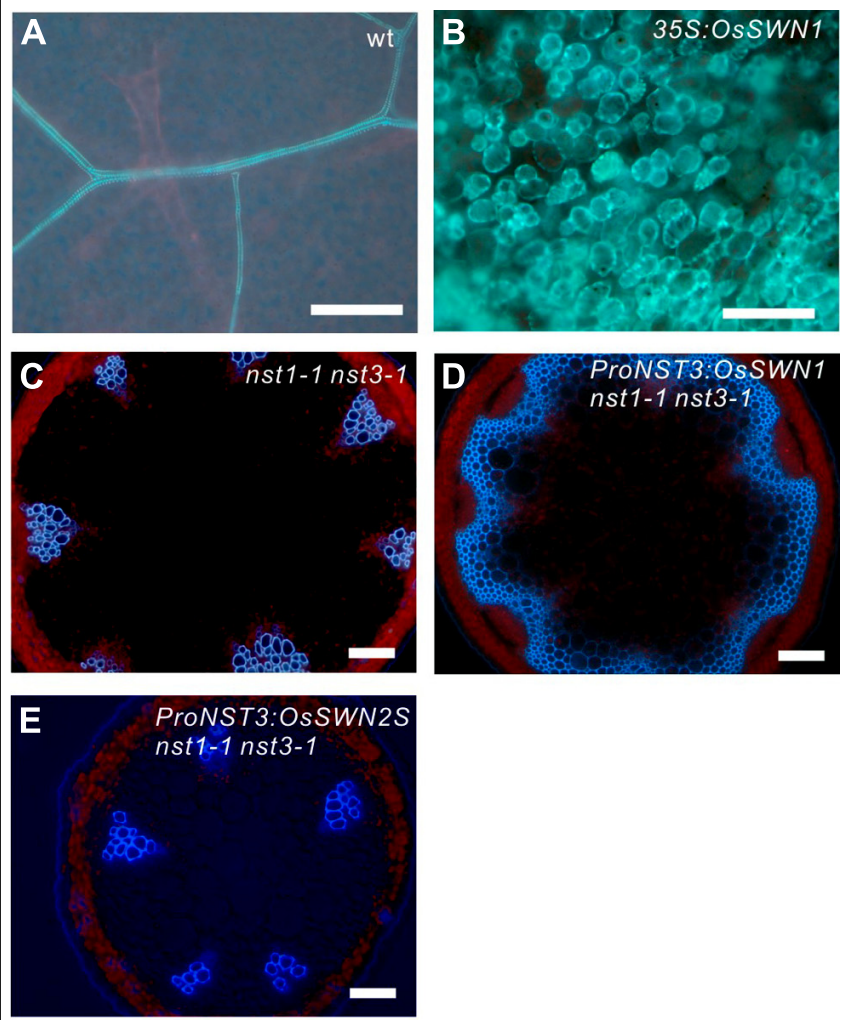

$\mathbf{F}$

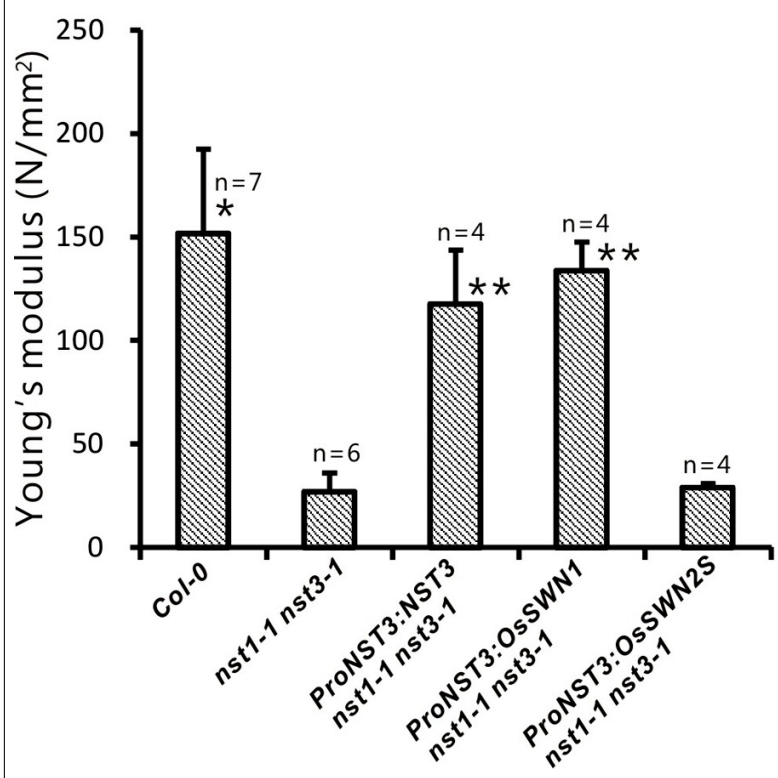

FIGURE 2 | OsSWN1 but not OsSWN2S restored the phenotype of nst1-1 nst3-1. (A-E) Fluorescence images under UV illumination. Blue auto-fluorescence represents lignin. Wild-type leaf (A), leaf of 35S: OsSWN1 Arabidopsis (B), cross section of stem of nst1-1 nst3-1 double mutant (C), nst1-1 nst3-1 ProNST3:OsSWN1 (D) and nst1-1 nst3-1 Pro NST3:OsSWN2S Arabidopsis (E). Bars represent $100 \mu \mathrm{m}$. (F) Comparison of physical strength (Young's modulus) of inflorescence stem. "*" and "**" indicate values significantly different from the nst1-1 nst3-1 mutant by Welch's $t$-test with $P<0.05$ and 0.01 , respectively.

\section{THE OSSWN2S CHIMERIC REPRESSOR ALTERS SECONDARY WALL} FORMATION IN RICE

To analyze the role of OsSWN genes in rice and examine their potential utility for cell wall engineering in rice, we prepared transgenic rice lines that express chimeric repressors (OsSWNs-SRDX), which consist of each OsSWN fused with the modified plant specific repression domain [ethylene-responsive element binding factor-associated amphiphilic repression (EAR) motif] derived from SUPERMAN (SRDX: LDLDLELRLGFA; Hiratsu et al., 2003). The resulting chimeric repressor is expected to work as a strong dominant-negative transcription factor that represses the expression of its target genes and induces a loss-of-function phenotype (Hiratsu etal., 2003). Neither OsSWN1-SRDX nor OsSWN2S$S R D X$ induced apparent abnormalities when expressed under the control of promoters derived from the rice actin gene or the maize ubiquitin gene. We cannot exclude the possibility that the transgene was not properly expressed in the plants because we did not examine transgene expression. However, our results are consistent with results in Arabidopsis, in which the CaMV 35S promoter, which induces ubiquitous expression, was not efficient in inducing a loss-of-function phenotype in fiber cells with a NST1-SRDX construct (Mitsuda et al., 2005, 2007). Therefore we next tested the OsSWN2 promoter, which is preferentially active in the vascular bundle (Figures 1B,D,F), and found that ProOsSWN2:OsSWN2S$S R D X$ caused severe retardation of shoot growth and rolling of vegetative leaves, resulting in needle-like leaf shape, 4-6 weeks after culture under normal water conditions. In addition, the rolled leaves of ProOsSWN2:OsSWN2S-SRDX lines turned brown at the maximum tillering stage. We describe this phenotype of ProOsSWN2:OsSWN2S-SRDX as "para-wilting"; the para-wilting phenotype was observed in 499 out of 568 ProOsSWN2:OsSWN2SSRDX transgenic plants but never observed in 779 control transgenic plants expressing the ProOsSWN2:GUS construct and 396 ProOsSWN2:OsSWN1-SRDX transgenic plants (Table 1, Figures 4A,B).

Because the OsSWN2 promoter is active in the vascular bundle, we examined water transport in the ProOsOSWN2:OsSWN2SSRDX plants using a tracer, red Fantasy dye solution. Even though no morphological abnormalities were observed in ProOsSWN2:OsSWN2S-SRDX rice leaves at 1-2 weeks after cultivation in the greenhouse, the excised shoots from transgenic plants did not absorb water as fast as the those from control transgenic plants (Figure 4C). Quantification of dye uptake supported this observation (Figure 4D). These data strongly suggest that water transport was severely impaired in these plants. This might be partly related to incomplete development of vascular vessels, as shown previously in Arabidopsis plants that expressed 35S:VND7SRDX (Kubo et al., 2005), since detailed examination of cross sections of leaf blades revealed less accumulation of lignin in the transgenic plants (Figures $4 \mathrm{E}, \mathbf{F}$ ).

Next, we expressed the chimeric repressors under control of the OsSWN1 promoter, which is preferentially active in several layers of sclerenchymatous cells beneath the leaf blade epidermis and shows little activity in vascular vessels. Because OsSWN2S-SRDX effectively induced abnormalities in the experiment described above, we focused on OsSWN2-SRDX in this experiment. 192 out of 471 ProOsSWN1:OsSWN2S-SRDX rice plants exhibited an 
A

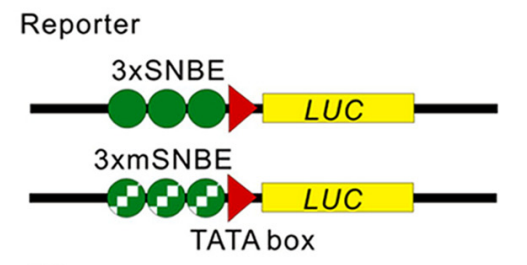

Effector

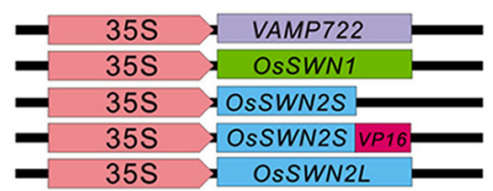

C

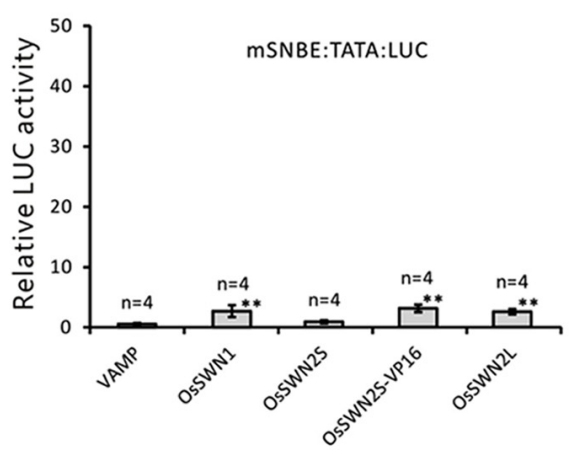

FIGURE 3 | OsSWN1 and OsSWN2L but not OsSWN2S can activate transcription. (A) Schematic of constructs used in the reporter-effector transient assay in Arabidopsis leaf protoplasts. "SNBE" and "mSNBE" represent the binding sequence for NST transcription factors and a mutated version of the binding site, respectively. "LUC" represents firefly luciferase, which was used as the reporter in this experiment. VAMP722, which localizes to the vacuolar membrane (Uemura etal., 2004), was employed as the negative control. (B, C) Relative LUC activity of the
B

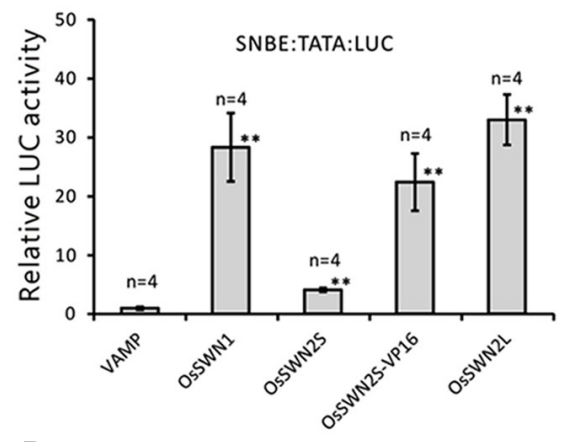

D

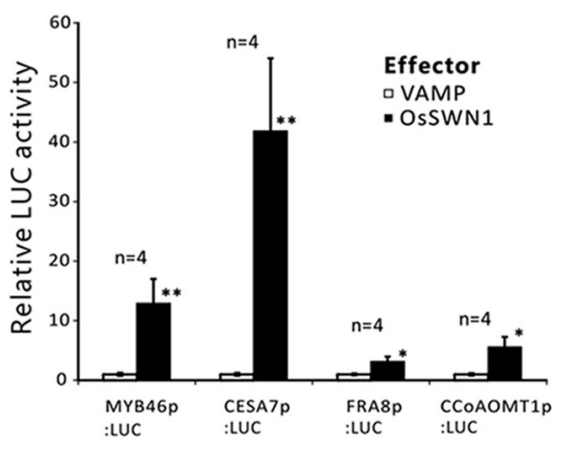

reporter constructs shown in (A) when each effector was cotransfected into Arabidopsis leaf protoplasts. LUC activity when the negative control was cotransfected was set to 1 in (B-D). (D) Relative LUC activity of the reporter constructs indicated on the $X$ axis when 35S:OsSWN1 or 35S:VAMP722 was cotransfected into Arabidopsis leaf protoplast. Error bars indicate SD. "*" and "**" indicate values significantly different from the negative control by Welch's $t$-test with $P<0.05$ and 0.01 , respectively. apparent drooping phenotype (Table 2; Figures 5A,B), a slight decrease in height (length of leaves). Detailed examination of leaf cross sections of the ProOsSWN1:OsSWN2S-SRDX rice plants revealed a reduction of secondary wall thickenings in the sclerenchymatous cells that form cortical layers beneath the epidermis and in bundle sheath fibers surrounding vascular vessels in xylem (Figures 5C-F). Moreover, transmission electron microscopy showed that the secondary walls were thinner in the transgenic rice plants (Figure 5G). Staining of the cross sections with phloroglucinol, which specifically stains lignin polymers, revealed reduced accumulation of lignin in the ProOsSWN1:OsSWN2S$S R D X$ rice plants (Figures 5C,D). We quantified the lignin content of culms by the acetyl-bromide method and found that it was reduced more than $20 \%$ in the transgenic plants compared to the control plants (Figure 5H). We further examined the neutral sugar compositions of the culms using liquid chromatography and found that TFA-soluble xylose was significantly reduced, but TFA-soluble arabinose presumably derived from arabinoxylan was not changed (Figures 5I,J), suggesting that xylan content was reduced in the cell walls of the ProOsSWN1:OsSWN2S-SRDX rice plants. Because some cultivars of rice and related monocot species are consumed as forage, we examined the ADF value, which shows the digestibility of the plant, with higher numbers indicating a higher lignin and crystalline-cellulose content, and therefore lower digestibility. Indeed, the ADF value was also significantly reduced in the ProOsSWN1:OsSWN2S-SRDX rice plants (Figure 5K). Also, the enzymatic saccharification rate of the cellulosic material was higher in the ProOsSWN1:OsSWN2S-SRDX rice plants than in the control transgenic plants (Figure $5 \mathrm{~L}$ ). The digestibility as forage was also significantly enhanced in the ProOsSWN1:OsSWN2S-SRDX transgenic rice (Figure 5M). These data suggest possible mechanisms for future genetic improvement of monocotyledonous forage and bioenergy species using this gene construct.

\section{DISCUSSION}

In this study, to explore the possibility of genetic engineering to improve the cell wall of monocots, we examined rice orthologs of the Arabidopsis NST transcription factors that regulate secondary wall formation. We found that OsSWN1 and OsSWN2 are expressed in cells where secondary cell walls are formed and can alter secondary cell wall formation in rice. Ectopic expression 
Table 1 | Para-wilting phenotype of the ProOsSWN2:OsSWN2S-SRDX rice plants.

\begin{tabular}{llll}
\hline $\begin{array}{l}\text { Transgenic } \\
\text { population }\end{array}$ & $\begin{array}{l}\text { Number of } \\
\text { plants showing } \\
\text { para-wilting*1 }\end{array}$ & $\begin{array}{l}\text { Total number of } \\
\text { hygromycin- } \\
\text { resistant plants }\end{array}$ & $\begin{array}{l}\text { Percentage } \\
\text { showing } \\
\text { para-wilting (\%) }\end{array}$ \\
\hline ProOsSWN2:GUS & & \\
1 & 0 & 228 & 0 \\
2 & 0 & 207 & 0 \\
3 & 0 & 145 & 0 \\
4 & 0 & 199 & 0 \\
Total & 0 & 779 & $0 \pm 0^{* 2}$ \\
ProOsSWN2:OsSWN2S-SRDX & & \\
1 & 163 & 177 & 92.1 \\
2 & 155 & 182 & 85.2 \\
3 & 181 & 209 & 86.6 \\
Total & 499 & 568 & $88 \pm 2.6^{* 2}$ \\
ProOsSWN2:OsSWN1-SRDX & & 0 \\
\hline Total & 0 & 396 & 0 \\
\hline & 0 & 396 &
\end{tabular}

*1 Para-wilting: leaves rolling into needle-like shape and browning under normal water conditions. Number of plants showing para-wilting was determined after 18-24 weeks of cultivation in the greenhouse. Leaves started to roll after 46 weeks of cultivation.

${ }^{* 2}$ Mean $\pm S E(n=3$ or 4$)$.

Table 2 | Drooping leaf phenotype of the ProOsSWN1: OSSWN2S-SRDX rice plants.

\begin{tabular}{llll}
\hline $\begin{array}{l}\text { Transgenic } \\
\text { line }\end{array}$ & $\begin{array}{l}\text { Number of plants } \\
\text { that showed } \\
\text { drooping leaves }\end{array}$ & $\begin{array}{l}\text { Total number of } \\
\text { hygromycin- } \\
\text { resistant plants }\end{array}$ & $\begin{array}{l}\text { Percentage with } \\
\text { drooping leaf- } \\
\text { phenotype (\%) }\end{array}$ \\
\hline $\begin{array}{l}\text { ProOsSWN1:GUS } \\
\text { Event no. }\end{array}$ & 0 & 231 & 0 \\
1 & & & \\
2 & 0 & 193 & 0 \\
3 & 0 & 255 & 0 \\
4 & 0 & 166 & 0 \\
Total & 0 & 845 & $0 \pm 0 * 1$ \\
ProOsSWN1:OsSWN2S-SRDX & & \\
\hline Event no. & 103 & 204 & 50.5 \\
1 & & & 43.5 \\
2 & 47 & 108 & 26.4 \\
3 & 42 & 159 & $40.1 \pm 8.8 * 1$ \\
Total & 192 & 471 & \\
\hline
\end{tabular}

${ }^{* 1}$ Mean $\pm S E(n=3$ or 4$)$

of OsSWN1 induced secondary wall formation in Arabidopsis and OsSWN2S chimeric repressors driven by the OsSWN1 promoter reduced secondary wall formation in rice. These results might

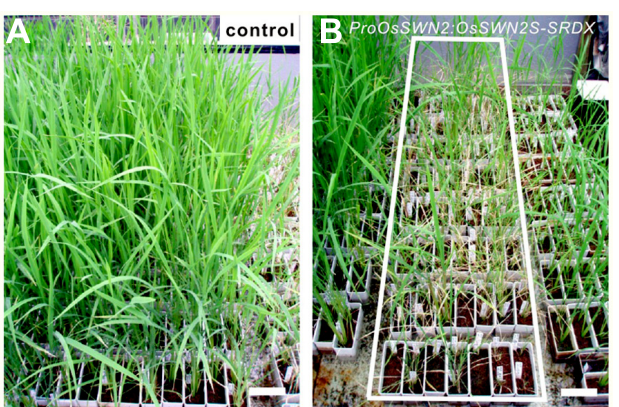

C
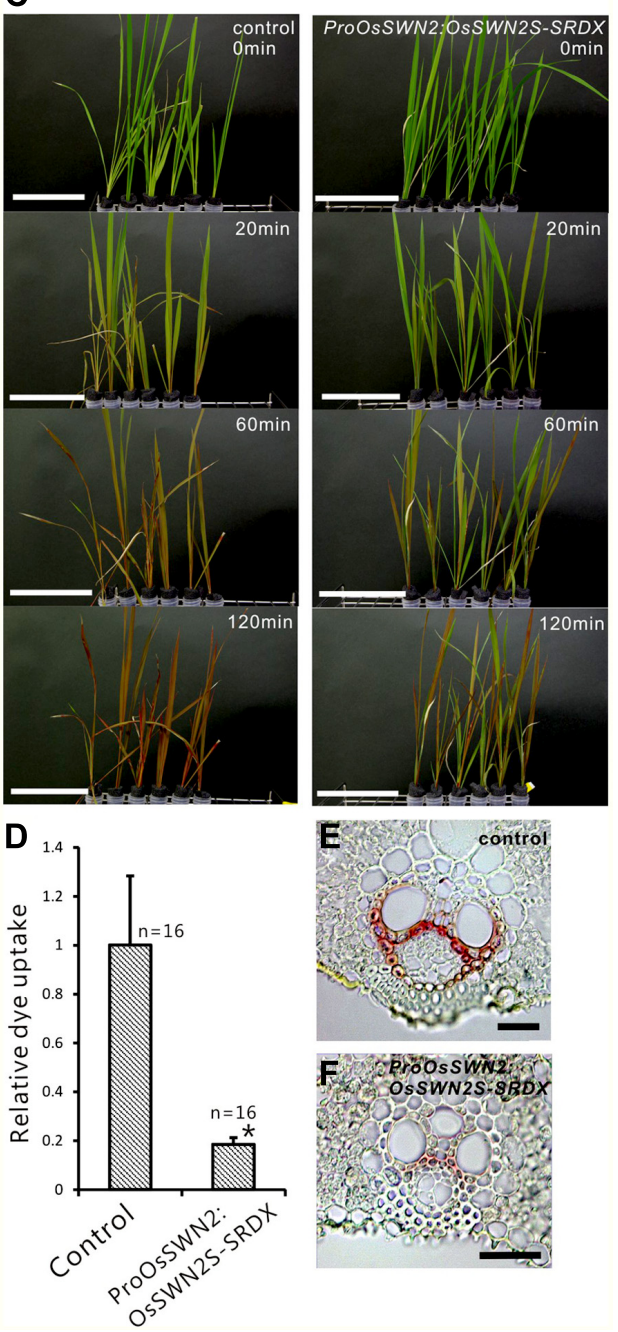

FIGURE 4 | ProOsSWN2:OsSWN2S-SRDX rice plants are defective in water transport. (A) ProOsSWN2:GUS rice plants (control). (B) ProOsSWN2: OsSWN2S-SRDX rice plants, indicated by the white rectangle. (C) Time-course examination of water uptake of shoots excised from the ProOsSWN2:OsSWN2S-SRDX plants before the onset of leaf rolling (1-2 weeks culture after budding). Water with a red tracer dye was used in the experiment. Bars in (A-C) represent $10 \mathrm{~cm}$. (D) Relative dye uptake by ProOsSWN2:OsSWN2S-SRDX plants compared to control plants (set to 1). Error bars represents standard error. "*" indicates values considered to be significantly different from control by Welch's $t$-test with $P<0.05$. (E, F) Cross sections of leaf of control plants (E) and ProOsSWN1:OsSWN2S-SRDX rice plants (F) stained with phloroglucinol to detect lignin. Bars in (E, F) represent $100 \mu \mathrm{m}$ 


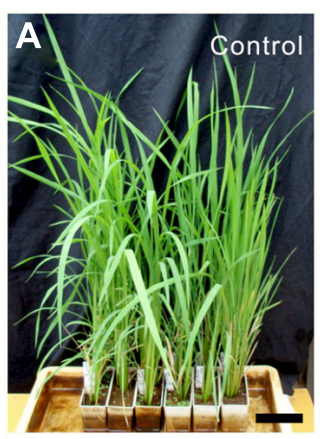

G

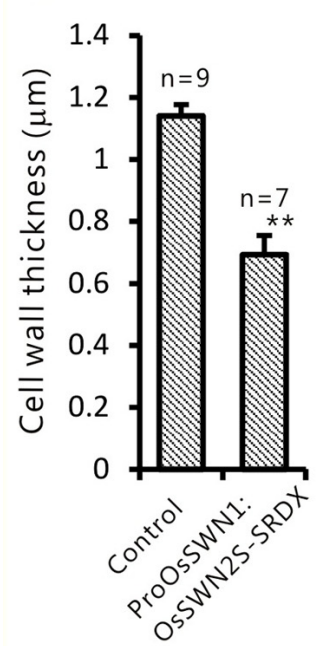

$\mathbf{J}$

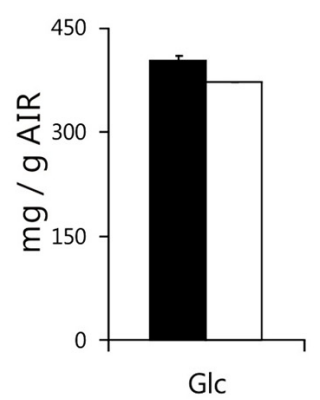

Control

$\square$ ProOsSWN1:

OsSWN2S-SRDX

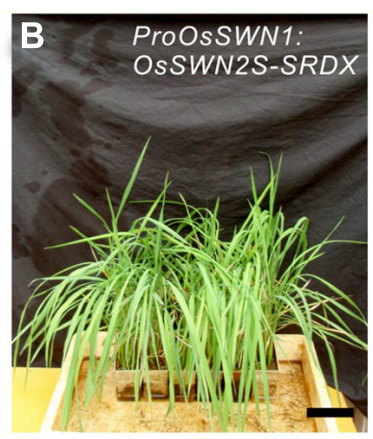

H

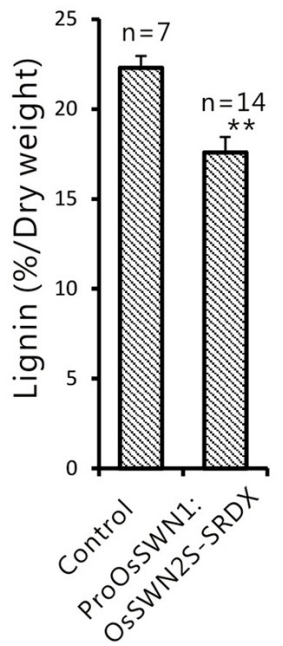

K

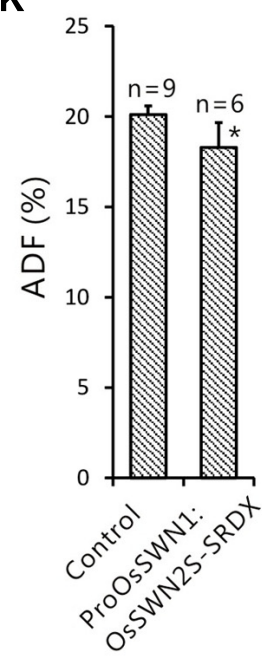

I

$\mathbf{L}$

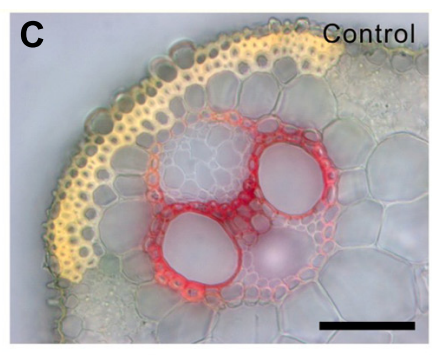

D ProOsSWN1:OSSWN2S-SRDX

\section{E}
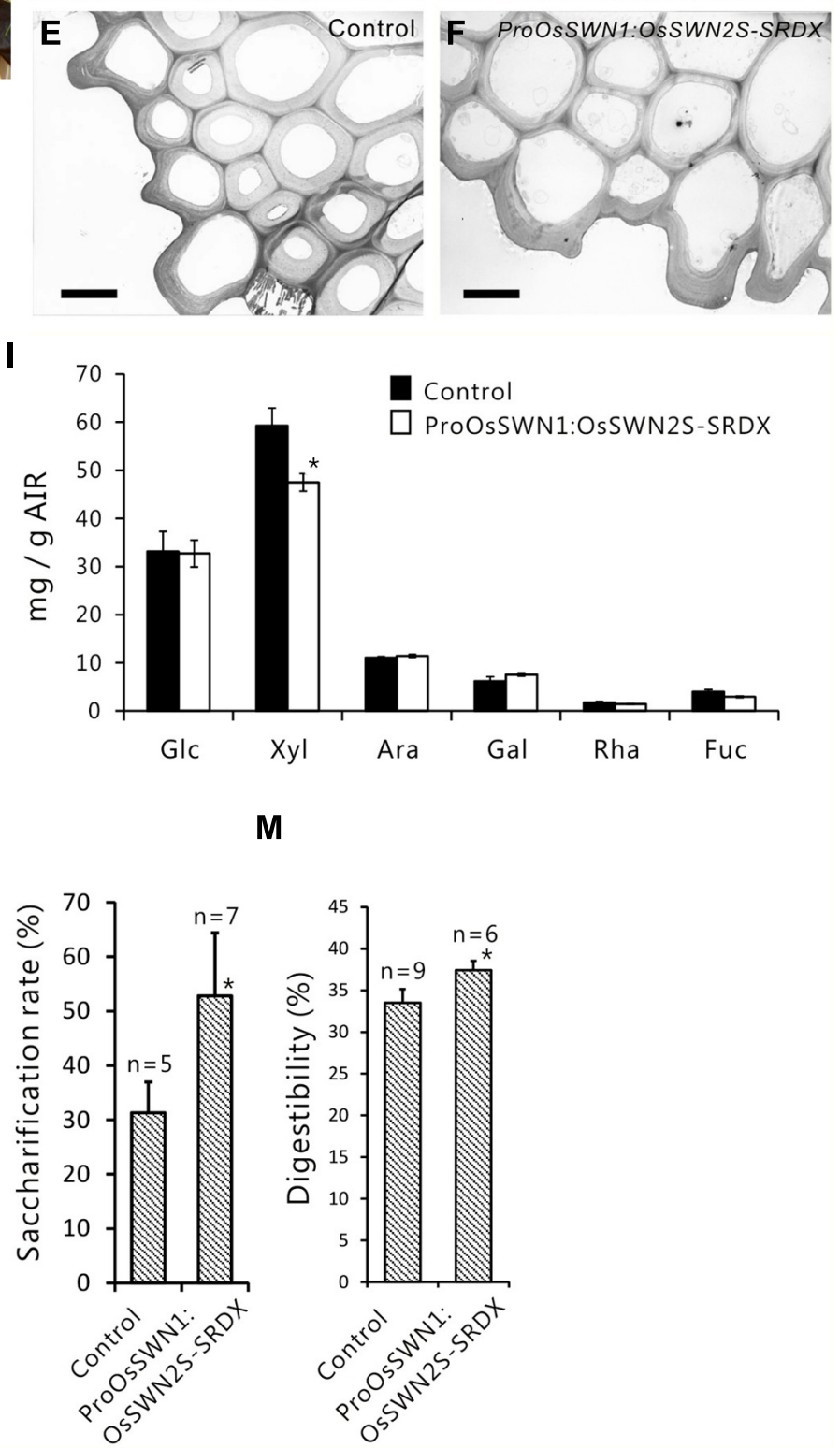

FIGURE 5 | Reduced secondary cell walls in ProOsSWN1:OsSWN2SSRDX rice. (A) ProOsSWN1:GUS rice plants (control). (B) ProOsSWN1: OsSWN2S-SRDX rice plants. (C-F) Cross sections of leaves of control plants (C, E) and ProOsSWN1:OsSWN2S-SRDX rice plants (D, F) stained with phloroglucinol to detect lignin (C, D) or observed by transmission electron microscopy (E, F). (G, H, K-M) Thickness of secondary walls (G), lignin content $(\mathbf{H})$, the ADF value (K), saccharification rate (L) and digestibility as forage (M) of ProOsSWN1:GUS rice plants (control) and
ProOsSWN1:OsSWN2S-SRDX rice plants. (I, J) Cell wall sugar composition of TFA soluble fraction (I) and TFA insoluble fraction (J) in alcohol insoluble residues (AIR). Sugar composition was analyzed in AIR of ProOsSWN1:GUS [control (black, $n=5)$ ] and ProOsSWN1: OsSWN2S-SRDX (white, $n=11$ ). "*" and "**" indicate $P$ value of Welch's $t$-test $<0.05$ or 0.01 , respectively. Error bars indicate $S D$ in (G, $\mathbf{H}, \mathbf{K}-\mathbf{M})$, SE in (I) and (J). Bars represent $10 \mathrm{~cm}$ in (A) and (B), $50 \mu \mathrm{m}$ in (C) and (D), $5 \mu \mathrm{m}$ in (E) and (F). 
reflect their abilities to activate transcription and we found that OsSWN1 can strongly activate transcription. However, OsSWN2S does not activate transcription, even though it can bind to the same cis-element as OsSWN1. It is likely that OsSWN1-SRDX did not function as a repressor in our assays because OsSWN1 itself can strongly activate transcription; this may counteract the negative activity of SRDX. The extent of ectopic secondary wall formation was greatest in the Arabidopsis plants overexpressing OsSWN1, compared to the other transgenic lines tested. In addition, we used the SRDX sequence, which is mainly used in Arabidopsis, and which may not function well in rice. However, OsSWN2S-SRDX efficiently suppressed secondary wall formation, probably because OsSWN2S has no endogenous transcriptional activation activity in our assays to counteract SRDX function. By contrast, OsSWN2L, the recently identified longer version of OsSWN2, has comparable transcriptional activation activity to OsSWN1. These results suggest that either: (i) OsSWN2L functions in planta but OsSWN2S does not function, or (ii) OsSWN2L promotes, and OsSWN2S inhibits secondary wall deposition in planta to fine-tune the formation of secondary wall, similar to a mechanism previously suggested in poplar (Lin et al., 2012).

OsSWNs clearly do not belong in the VND subgroup, which functions in the formation of vascular vessels, but rather are classified in the NST subgroup, which mainly functions in the fiber cells in Arabidopsis. However, the OsSWN promoters are active in cells that will form vascular vessels. For example, the rice plants expressing OsSWN2S-SRDX driven by the OsSWN2 promoter showed a severe defect in water transport. There are several rice genes that apparently belong to the VND subgroups, are strongly expressed in vascular bundles, and can restore the drooping phenotype of nst1 nst3 double mutants (Zhong et al., 2011a). This supports the idea that OsSWN1/2 should not be classified as a VND protein, even if the OsSWN2 promoter is highly active in vascular vessels. As suggested previously for poplar (Ohtani et al., 2011; Zhong etal., 2011b), the classification of NST and VND subgroups may also be ambiguous in rice.

Reducing the recalcitrance of plant material is emerging as a key issue for plant biotechnology in this decade, both for

\section{REFERENCES}

Abe, A. (1988). Feed analyses based on the carbohydrates and its application to the nutritine value of feeds. Mem. Nat. Inst. Anim. Ind. 2, 1-75.

Albersheim, P., Nevins, D. J., English, P. D., and Karr, A. (1967). A method for the analysis of sugars in plant cell-wall polysacharides in plant cellwall polysaccharides by gas-liquid chromatography. Carbohydr. Res. 5, 340-345. doi: 10.1016/S00086215(00)80510-8

Bhargava, A., Mansfield, S. D., Hall, H. C., Douglas, C. J., and Ellis, B. E. (2010). MYB75 functions in regulation of secondary cell wall formation in the Arabidopsis inflorescence stem. Plant Physiol. 154, 1428-1438. doi: 10.1104/pp.110.162735
Carpita, N. C., and Gibeaut, D. M. (1993). Structural models of primary cell walls in flowering plants: consistency of molecular structure with the physical properties of the walls during growth. Plant J. 3, 1-30. doi: 10.1111/j.1365313X.1993.tb00007.x

Cassan-Wang, H., Goué, N., Saidi, M. N., Legay, S., Sivadon, P., Goffner, D. et al. (2013). Identification of novel transcription factors regulating secondary cell wall formation in Arabidopsis. Front Plant Sci. 4:189. doi: 10.3389/fpls.2013.00189

Cleland, R. (1967). Extensibility of isolated cell walls: measurement and changes during cell elongation. Planta 74, 197-209. doi: 10.1007/ BF00384842 production of lignocellulosic bioethanol and for digestibility of forage. The ProOsSWN1:OsSWN2S-SRDX transgenic rice line developed in this study showed reduced lignin content, enhanced forage digestibility and increased saccharification rate. This result is consistent with the previous finding in Arabidopsis that the nst1-1 nst3-1 double mutant and ProNST3:NST1-SRDX transgenic plants showed an increased saccharification rate (Iwase et al., 2009). In Arabidopsis, even though the total glucan content was not reduced, the ProNST3:NST1-SRDX plants could not stand erect at all and were quite fragile. The transgenic plants generated here show reduced lignin and xylose content but were more sturdy. Rice contains a large amount of silica, which might help support plants with reduced lignocellulose and the transgenic plants also contained residual lignocellulose, as a result of incomplete suppression by OsSWNSRDX.

The monocot secondary wall is not conspicuous, but it is unequivocally important for bioethanol production and forage quality. In this study, we demonstrated that two OsSWN transcription factors regulate secondary wall formation in rice and therefore may be useful to improve cell wall quality in monocot crops (lower contents of lignin and xylan). We expect further studies of the secondary wall in monocots will improve our understanding of plant cell wall formation, structure, and function and allow key improvements for forage and biofuel crops.

\section{ACKNOWLEDGMENTS}

The authors thank Ms. Yoshimi Sugimoto (AIST), Ms. Akiko Kuwazawa (AIST), Ms. Sumiko Takahashi (AIST), Ms. Takako Morimoto (Taisei Co.) and Ms. Noriko Ushiyama (Taisei Co.) for their skillful technical assistance and Dr. Noboru Endo (Taisei Co.) for his useful suggestion. The authors also appreciate the Rice Genome Resource Center (RGRC), Japan for distributing full-length cDNA clones. This work was supported by the Research and Development Program for New Bio-industry Initiatives from the Bio-oriented Technology Research Advancement Institution in Japan (to M. O. T. and T. T.); Advanced Low Carbon Technology Research and Development Program (ALCA) by Japan Science and Technology Agency (JST) (to N. M.).

Clough, S. J., and Bent, A. F (1998). Floral dip: a simplified method for agrobacteriummediated transformation of Arabidopsis thaliana. Plant J. 16, 735743. doi: 10.1046/j.1365-313x.1998. 00343.x

Fujikawa, Y., and Kato, N. (2007). Split luciferase complementation assay to study protein-protein interactions in Arabidopsis protoplasts. Plant J. 52, 185-195. doi: 10.1111/j.1365313X.2007.03214.X

Hatfield, R. D., Grabber, J., Ralph, J., and Brei, K. (1999). Using the acetyl bromide assay to determine lignin concentrations in herbaceous plants: some cautionary notes. J. Agric. Food Chem. 47, 628-632. doi: 10.1021/jf9808776
Hirano, K., Kotake, T., Kamihara, K., Tsuna, K., Aohara, T., Kaneko, Y., et al. (2010). Rice BRITTLE CULM 3 (BC3) encodes a classical dynamin OsDRP2B essential for proper secondary cell wall synthesis. Planta 010-1145-6

Hiratsu, K., Matsui, K., Koyama, T., and Ohme-Takagi, M. (2003). Dominant repression of target genes by chimeric repressors that include the EAR motif, a repression domain, in Arabidopsis. Plant J. 34, 733739. doi: 10.1046/j.1365-313X.2003. 01759.x

Iiyama, K., and Wallis, A. F. A. (1988). An improved acetyl bromide procedure for determining lignin in woods and wood pulps. Wood 232, 95-108. doi: 10.1007/s00425- 
Sci. Technol. 22, 271-280. doi: 10.1007/BF00386022

Iwase, A., Hideno, A., Watanabe, K. Mitsuda, N., and Ohme-Takagi, M. (2009). A chimeric NST repressor has the potential to improve glucose productivity from plant cell walls. J. Biotechnol. 142, 279-284. doi: 10.1016/j.jbiotec.2009.05.011

Johnson, D. B., Moore, W. E., and Zank, L. C. (1961). The spectrophotometric determination of lignin in small wood samples. Tappi 44, 793-798.

Katoh, K., Misawa, K., Kuma, K., and Miyata, T. (2002). MAFFT: a novel method for rapid multiple sequence alignment based on fast Fourier transform. Nucleic Acids Res. 30, 3059-3066. doi: 10.1093/nar/gkf436

Kawai, T., Nakazawa, H., Ida, N., Okada, H., Tani, S., Sumitani, J., et al. (2012). Analysis of the saccharification capability of high-functional cellulase JN11 for various pretreated biomasses through a comparison with commercially available counterparts. J. Ind. Microbiol. Biotechnol. 39, 1741-1749. doi: 10.1007/s10295012-1195-9

Keijzer, C. J. (1987). The processes of anther dehiscence and pollen dispersal. The opening mechanism of longitudinally dehiscing anthers. New Phytol. 105, 487-498. doi: 10.1111/j.1469-8137.1987.tb00886.x

Ko, J. H., Kim, W. C., and Han, K. H. (2009). Ectopic expression of MYB46 identifies transcriptional regulatory genes involved in secondary wall biosynthesis in Arabidopsis. Plant J. 60, 649-665. doi: 10.1111/j.1365313X.2009.03989.x

Ko, J. H., Kim, W. C., Kim, J. Y., Ahn, S. J., and Han, K. H. (2012). MYB46-mediated transcriptional regulation of secondary wall biosynthesis. Mol. Plant 5, 961-963. doi: $10.1093 / \mathrm{mp} / \mathrm{sss} 076$

Ko, J. H., Yang, S., Park, A. H., Lerouxel, O., and Han, K. H. (2007). ANAC012, a member of the plant-specific NAC transcription factor family, negatively regulates xylary fiber development in Arabidopsis thaliana. Plant J. 50, 1035-1048. doi: 10.1111/j.1365313X.2007.03109.x

Kotake, T., Aohara, T., Hirano, K., Sato, A., Kaneko, Y., Tsumuraya, Y., et al. (2011). Rice brittle culm 6 encodes a dominant negative form of CesA protein that perturbs cellulose synthesis in secondary cell walls. J. Exp. Bot. 62, 2053-2062. doi: 10.1093/jxb/ erq395

Kubo, M., Udagawa, M., Nishikubo, N., Horiguchi, G., Yamaguchi, M., Ito, J., et al. (2005). Transcription switches for protoxylem and metaxylem vessel formation. Genes Dev. 19, 1855 1860. doi: 10.1101/gad.1331305

Li, E., Wang, S., Liu, Y., Chen, J. G., and Douglas, C. J. (2011). OVATE FAMILY PROTEIN4 (OFP4) interaction with KNAT7 regulates secondary cell wall formation in Arabidopsis thaliana. Plant J. 67, 328-341. doi: 10.1111/j.1365-313X.2011.04595.X

Li, Y., Qian, Q., Zhou, Y., Yan, M., Sun, L., Zhang, M., et al. (2003). BRITTLE CULM1, which encodes a COBRAlike protein, affects the mechanical properties of rice plants. Plant Cell 15, 2020-2031. doi: 10.1105/tpc.011775

Lin, Q., Lin, Y. C., Sun, Y. H., Song, J., Chen, H., Zhang, X. H., et al. (2012). Splice variant of the SND1 transcription factor is a dominant negative of SND1 members and their regulation in Populus trichocarpa. Proc. Natl. Acad. Sci. U.S.A. 109, 14699-14704. doi: 10.1073/pnas.1212977109

Mitsuda, N., Hiratsu, K., Todaka, D., Nakashima, K., YamaguchiShinozaki, K., and Ohme-Takagi, M. (2006). Efficient production of male and female sterile plants by expression of a chimeric repressor in Arabidopsis and rice. Plant Biotech. J. 4, 325-332. doi: 10.1111/j.14677652.2006.00184.x

Mitsuda, N., Iwase, A., Yamamoto, H., Yoshida, M., Seki, M., Shinozaki, K., etal. (2007). NAC transcription factors, NST1 and NST3, are key regulators of the formation of secondary walls in woody tissues of Arabidopsis. Plant Cell 19, 270-280. doi: 10.1105/tpc.106.047043

Mitsuda, N., and Ohme-Takagi, M (2008). NAC transcription factors NST1 and NST3 regulate pod shattering in a partially redundant manner by promoting secondary wall formation after the establishment of tissue identity. Plant J. 56, 768-778. doi: 10.1111/j.1365-313X.2008.03633.x

Mitsuda, N., Seki, M., Shinozaki, K., and Ohme-Takagi, M. (2005). The NAC transcription factors NST1 and NST2 of Arabidopsis regulate secondary wall thickenings and are required for anther dehiscence. Plant Cell 17, 2993-3006. doi: 10.1105/tpc.105.036004

Morrison, I. M. (1972). Improvements in the acetyl bromide technique to determine lignin and digestibility and its application to legumes. J. Sci. Food Agric. 23, 1463-1469. doi: 10.1002/jsfa.2740231211

Murakami, T., Shimano, S., Kaneda, S., Nakajima, M., Urashima, Y., and Miyoshi, N. (2006). Multicolor staining of root systems in pot culture. Soil Sci. Plant Nutr. 52, 618-622. doi: 10.1111/j.1747-0765.2006.00078.x
Nagaya, S., Kawamura, K., Shinmyo, A., and Kato, K. (2010). The HSP terminator of Arabidopsis thaliana increases gene expression in plant cells. Plant Cell Physiol. 51, 328-332. doi: $10.1093 / \mathrm{pcp} / \mathrm{pcp} 188$

Ohtani, M., Nishikubo, N., Xu, B., Yamaguchi, M., Mitsuda, N., Goue, N. et al. (2011). A NAC domain protein family contributing to the regulation of wood formation in poplar. Plant J. 67, 499-512. doi: 10.1111/j.1365 313X.2011.04614.X

Satoh, K., Doi, K., Nagata, T., Kishimoto, N., Suzuki, K., Otomo, Y., etal. (2007). Gene organization in rice revealed by full-length cDNA mapping and gene expression analysis through microarray. PLoS ONE 2:e1235. doi: 10.1371/journal.pone.0001235

Schmer, M. R., Vogel, K. P., Mitchell, R. B., and Perrin, R. K. (2008). Net energy of cellulosic ethanol from switchgrass. Proc. Natl. Acad. Sci. U.S.A. 105, 464-469. doi: 10.1073/pnas.0704767105

Soyano, T., Thitamadee, S., Machida, Y., and Chua, N. H. (2008). ASYMMETRIC LEAVES2-LIKE19/ LATERAL ORGAN BOUNDARIES DOMAIN30 and ASL20/LBD18 regulate tracheary element differentiation in Arabidopsis. Plant Cell 20, 3359-3373. doi: 10.1105/tpc.108.061796

Tamura, K., Peterson, D., Peterson, N., Stecher, G., Nei, M., and Kumar, S. (2011). MEGA5: molecular evolutionary genetics analysis using maximum likelihood, evolutionary distance, and maximum parsimony methods. Mol. Biol. Evol. 28, 27312739. doi: $10.1093 / \mathrm{molbev} / \mathrm{msr} 121$

The Rice Full-Length cDNA Consortium. (2003). Collection, mapping, and annotation of over $28,000 \mathrm{cDNA}$ clones from japonica rice. Science 301, 376-379. doi: 10.1126/science. 1081288

Uemura, T., Ueda, T., Ohniwa, R. L. Nakano, A., Takeyasu, K., and Sato, M. H. (2004). Systematic analysis of SNARE molecules in Arabidopsis: dissection of the post-golgi network in plant cells. Cell Struct. Funct. 29, 49-65. doi: 10.1247/csf.29.49

Van Soest, P. J. (1963). Use of detergents in the analysis of fibrous feeds II. A rapid method for determination of fiber and lignin. J. Assoc. Off. Anal. Chem. 46, 829 .

Wang, H., Avci, U., Nakashima, J., Hahn, M. G., Chen, F., and Dixon, R. A. (2010). Mutation of WRKY transcription factors initiates pith secondary wall formation and increases stem biomass in dicotyledonous plants. Proc. Natl. Acad. Sci. U.S.A. 107, 22338-22343. doi: $10.1073 /$ pnas.1016436107

Yokoyama, R., and Nishitani, K. (2004). Genomic basis for cell-wall diversity in plants. A comparative approach to gene families in rice and Arabidopsis. Plant Cell Physiol. 45, 1111-1121. doi: 10.1093/pcp/pch151

Zhao, Q., Gallego-Giraldo, L., Wang, H., Zeng, Y., Ding, S. Y., Chen, F., et al. (2010). An NAC transcription factor orchestrates multiple features of cell wall development in Medicago truncatula. Plant J. 63, 100-114. doi: 10.1111/j.1365-313X.2010.04223.x

Zhong, R., Demura, T., and Ye, Z. H. (2006). SND1, a NAC domain transcription factor, is a key regulator of secondary wall synthesis in fibers of Arabidopsis. Plant Cell 18, 3158-3170. doi: 10.1105/tpc.106.047399

Zhong, R., Lee, C., McCarthy, R. L., Reeves, C. K., Jones, E. G., and Ye, Z. H. (2011a). Transcriptional activation of secondary wall biosynthesis by rice and maize NAC and MYB transcription factors. Plant Cell Physiol. 52, 1856-1871. doi: $10.1093 /$ pcp/pcr 123

Zhong, R., Lee, C., and Ye, Z. H. (2010). Global analysis of direct targets of secondary wall NAC master switches in Arabidopsis. Mol. Plant 3, 1087-1103. doi: 10.1093/mp/ssq062

Zhong, R., McCarthy, R. L., Lee, C., and Ye, Z. H. (2011b). Dissection of the transcriptional program regulating secondary wall biosynthesis during wood formation in poplar. Plant Physiol. 157, 1452-1468. doi: 10.1104/pp.111. 181354

Zhong, R., Richardson, E. A., and Ye, Z. H. (2007). The MYB46 transcription factor is a direct target of SND1 and regulates secondary wall biosynthesis in Arabidopsis. Plant Cell 19, 27762792. doi: 10.1105/tpc.107.053678

Zhou, J., Lee, C., Zhong, R., and Ye, Z. H. (2009). MYB58 and MYB63 are transcriptional activators of the lignin biosynthetic pathway during secondary cell wall formation in Arabidopsis. Plant Cell 21, 248-266. doi: 10.1105/tpc. 108.063321

Conflict of Interest Statement: The authors declare that the research was conducted in the absence of any commercial or financial relationships that could be construed as a potential conflict of interest.

Received: 14 July 2013; accepted: 10 September 2013; published online: 01 October 2013. 
Citation: Yoshida K, Sakamoto S, Kawai T, Kobayashi Y, Sato K, Ichinose $Y$, Yaoi K, Akiyoshi-Endo $M$, Sato $H$, Takamizo T, Ohme-Takagi $M$ and Mitsuda $N$ (2013) Engineering the Oryza sativa cell wall with rice NAC transcription factors regulating secondary wall formation. Front. Plant Sci. 4:383. doi: 10.3389/fpls.2013.00383

This article was submitted to Plant Biotechnology, a section of the journal Frontiers in Plant Science.

Copyright (c) 2013 Yoshida, Sakamoto, Kawai, Kobayashi, Sato, Ichinose, Yaoi,
Akiyoshi-Endo, Sato, Takamizo, OhmeTakagi and Mitsuda. This is an openaccess article distributed under the terms of the Creative Commons Attribution License (CC BY). The use, distribution or reproduction in other forums is permitted, provided the original author(s) or licensor are credited and that the original publication in this journal is cited, in accordance with accepted academic practice. No use, distribution or reproduction is permitted which does not comply with these terms. 